\title{
Identification of four trp 1 gene variants murine pancreatic beta-cells
}

\author{
H. Sakura, F. M. A shcroft \\ University Laboratory of Physiology, Oxford, UK
}

Summary Insulin secretion is stimulated by glucose, hormones and neurotransmitters. Both activation of a non-selective cation current and activation of a $\mathrm{Ca}^{2+}$ current in response to depletion of intracellular $\mathrm{Ca}^{2+}$ stores have been suggested to play a role in this stimulation. The properties of these currents resemble those reported for the D rosophila genes trp and trpl. Using the reverse transcription polymerase chain reaction and Northern blot analysis we found that of the six mammalian trp-related genes (trp1-6), only trp1 was expressed at high levels in the mouse insulinoma cell line MIN6. We cloned the murine homologue of human trp1 from MIN6 cells and identified four variants $(\alpha, \beta, \gamma$ and $\delta)$, generated by alternative splicing near the N-terminus of the protein. In vitro translation showed that only the $\alpha$ and $\beta$ splice variants are efficiently expressed. The $\beta$ variant is the dominant form in MIN6 cells (and probably in mouse pancreatic islets), whereas the $\alpha$ variant is the major type in the mouse brain. The $\beta$ variant showed $99 \%$ identity to the human homologue at the amino acid level. [Diabetologia (1997) 40: 528532]

Keywords trp1, Ca-release activated channel, pancreatic beta cell, MIN6 cell, insulin secretion.
Insulin secretion from the pancreatic beta cell is stimulated by glucose, hormones and neurotransmitters [1]. Glucose is the primary physiological stimulus for insulin secretion. It acts by closing ATP-sensitive potassium (K-ATP) channels in the beta-cell plasma membrane. This produces a membrane depolarisation which opens voltage-dependent $\mathrm{Ca}^{2+}$ channels and the ensuing $\mathrm{Ca}^{2+}$ influx elevates $\left[\mathrm{Ca}^{2+}\right]_{\mathrm{i}}$ and so initiates insulin secretion. The inhibition of K-ATP channels cannot by itself explain the depolarization

Received: 4 December 1996 and in revised form: 3 February 1997

Corresponding author: Professor F.M. Ashcroft, University Laboratory of Physiology, Parks Road, Oxford OX1 3PT, UK Abbreviations: RT-PCR, Reverse transcriptase polymerase chain reaction; $\mathrm{I}_{\mathrm{CRAC}}, \mathrm{Ca}^{2+}$ release-activated current; K-ATP channel, ATP-sensitive potassium channel; trp, transient receptor potential; MIN, mouse insulinoma cells; HEK, human embryonic kidney cells; SDS, sodium dodecyl sulphate; VDCC, voltage-dependent calcium channel. induced by glucose. Rather, it is necessary to postulate that there is a resting inward current with a more positive equilibrium potential, which dominates the resting potential when K-ATP channels close. This background inward current has not been identified but the positive reversal potential suggests that it must be primarily carried by $\mathrm{Na}^{+}$and/or $\mathrm{Ca}^{2+}$ ions.

A number of hormones which potentiate insulin secretion are also believed to depolarise the betacell by activating an inward $\mathrm{Na}^{+}$-current. Among these are acetylcholine (ACh [2-5]) and the pituitary adenylate cyclase activating polypeptide (PACAP [6]). Although acetylcholine elevates inositol 1,4,5triphosphate $\left(\mathrm{IP}_{3}\right)$ and mediates $\mathrm{Ca}^{2+}$ release from intracellular stores, current evidence suggests that the $\mathrm{Na}^{+}$-current is not activated by $\mathrm{Ca}^{2+}$ and is independent of $\mathrm{Ca}^{2+}$-store depletion [5]. Depletion of beta-cell intracellular $\mathrm{Ca}^{2+}$ stores by exposure to low extracellular $\mathrm{Ca}^{2+}$, however, does activate a small non-selective inward current $[7,8]$. This current has been called $\mathrm{I}_{\mathrm{CRAC}}$ (for $\mathrm{Ca}^{2+}$-release-activated current). Depletion of intracellular $\mathrm{Ca}^{2+}$ stores by 
thapsigargin modifies the pattern of beta-cell electrical activity and $\left[\mathrm{Ca}^{2+}\right]_{\mathrm{i}}$ oscillations induced by glucose $[8,9]$.

The channel (or channels) responsible for the beta-cell background $\mathrm{Na}^{+}$-current, the $\mathrm{Na}^{+}$-current activated by hormones, and $\mathrm{I}_{\mathrm{CRAC}}$ have not been identified at the molecular level. The properties of these currents are, however, reminiscent of those produced by expression of the trp and trpl genes. The D rosophila gene product trp (transient receptor potential) encodes a putative plasma membrane $\mathrm{Ca}^{2+}$ channel. Expression of trp in heterologous systems enhances $\mathrm{Ca}^{2+}$ entry in response to depletion of intracellular $\mathrm{Ca}^{2+}$ stores with thapsigargin $[10,11]$. A related gene product, trpl (trp-like), encodes a constitutively active non-selective cation channel which is unaffected by store depletion [12]. Recently, mammalian homologues of trp and trpl have been identified [13-16] and the existence of six trp-related genes in the mouse genome (M trp1-6) has been reported by RT-PCR [17]. In this paper, therefore, we have examined the expression of the $M$ trp genes in the mouse insulinoma cell line MIN6, which constitutes a pure beta-cell population.

\section{Materials and methods}

I solation of trp fragments by RT-PCR. Poly (A) ${ }^{+}$RNA was purified from MIN6 cells (mouse insulinoma cells) and HEK293 cells (human embryonic kidney cells) using a FastTrack 2.0 Kit (Invitrogen, De Schelp, The Netherlands) and converted to cDNA using reverse transcriptase (RT). Two redundant primers, 5 '-TNGGNCCN(C/T)TNCA(A/G)AT(A/T/C)TC$3^{\prime}$ (sense) and 5'-CGNGC(A/G)AA(C/T)TTCCA(C/T)TC$3^{\prime}$ (antisense) were designed, which are common to all six trp genes and predicted to amplify $367-424$ bp fragments. For amplification of $\operatorname{trp} 4$ and trp 5, we also used $5^{\prime}$ TCTGCAGATATCTCTGGGAAGGATGC- ${ }^{\prime}$ ' (sense) and 5'-AAGCTTTGTTCGAGCAAATTTCCATTC-3' (antisense) primers. The PCR conditions consisted of 35 cycles of $94^{\circ} \mathrm{C}$ for $1 \mathrm{~min}, 50^{\circ} \mathrm{C}$ for $1 \mathrm{~min}$ and $72^{\circ} \mathrm{C}$ for $1 \mathrm{~min}$. Each $10 \mu \mathrm{l}$ PCR reaction contained $100 \mathrm{ng}$ of cDNA template, 10 pmol of each PCR primer, $0.2 \mathrm{mmol} / \mathrm{l}$ of each of the dNTPs, 0.25 units of Taq DNA polymerase (Promega, Madison, Wis., USA), $50 \mathrm{mmol} / 1 \mathrm{KCl}, 10 \mathrm{mmol} / \mathrm{l}$ Tris- $\mathrm{HCl}$ (pH 9.0), $0.1 \%$ Triton $\mathrm{X}-100$ and $1.5 \mathrm{mmol} / 1 \mathrm{MgCl}_{2}$. Since the PCR product exhibited multiple bands (because redundant primers were used: data not shown) we cut out the bands of 350-450 bp, which will contain all fragments amplified from M trp1-6. These PCR fragments were purified, subcloned into pT7Blue T-Vector (Novagen, Madison, Wis, USA) and sequenced.

Screening of CDNA library. A MIN6 cDNA library was constructed as described elsewhere [18] using a ZAP Express cDNA synthesis kit (Stratagene, La Jolla, Calif., USA). This library $\left(5 \times 10^{5}\right.$ phages $)$ was screened under low stringency conditions (hybridised with $30 \%$ formamide, $5 \times$ Denhardt's, $5 \times \operatorname{SSPE}\left(0 \cdot 75 \mathrm{~mol} / \mathrm{l} \mathrm{NaCl}, 50 \mathrm{mmol} / \mathrm{l} \mathrm{Na} \mathrm{PO}_{4}, \mathrm{pH}\right.$ 7 . 4) $100 \mu \mathrm{g} / \mathrm{ml}$ denatured salmon sperm DNA at $37^{\circ} \mathrm{C}$ and washed with $0.5 \times \mathrm{SSC}(75 \mathrm{mmol} / \mathrm{l} \mathrm{NaCl}, 7.5 \mathrm{mmol} / \mathrm{l} \mathrm{Na}$-citrate, $\mathrm{pH} 7 \cdot 0), 0.1 \%$ sodium dodecylsulphate (SDS) at room temperature). PBK-CMV plasmids containing a cDNA insert of a positive clone were excised using a helper phage (ExAssist, Stratagene, La Jolla, Calif., USA) and sequenced.

Northern blot analysis. The full length murine trp1 was hybridised with $2 \mu \mathrm{g}$ of MIN6 poly(A) ${ }^{+}$RNA, and with a Multiple Tissue Northern Blot (Clontech, Palo Alto, Calif., USA) containing $2 \mu \mathrm{g}$ of poly(A) ${ }^{+}$RNA from various mouse tissues according to the manufacturer's protocol. This was carried out under low (as described for library screening) or high (hybridised with $50 \%$ formamide, $10 \times$ Denhardt's, $5 \times \mathrm{SSPE}, 100 \mu \mathrm{g} /$ $\mathrm{ml}$ denatured salmon sperm DNA and $2 \%$ SDS at $42{ }^{\circ} \mathrm{C}$ and washed with $0.1 \% \times \mathrm{SSC}, 0.1 \% \mathrm{SDS}$ at room temperature) stringency conditions. Autoradiography was carried out for 2 days with intensifying screens. After washing out of the trp probe, filters were re-hybridised with $\beta$-actin as a control.

I dentification of splicing variants. Total RNA was isolated using TRI-Reagent (Molecular Research Centre, Oxford, UK) from mouse brain, kidney, and pancreatic islets and converted to cDNAs. Primer pairs, 5 '-TGTACCCGAGCACGGACCTC3 ' (sense) and 5 '-GCAGAACACAGTGTGCATTC-3' (antisense), were end-labelled using $\left[{ }^{32} \mathrm{P}\right] \gamma$-ATP and PCR was performed as above. Amplified products were subjected to electrophoresis using a $5 \%$ polyacrylamide gel and then to autoradiography.

In vitro translation. The cDNAs encoding each of the M trp1 variants were cloned into the $\mathrm{pBF}$ vector. In vitro translation was performed using a TNT Coupled Reticulocyte Lysate System (Promega Madison, Wis, USA). Plasmid DNA $(0.5 \mu \mathrm{g})$ was translated (reaction volume, $25 \mu \mathrm{l}$ ) using SP6 RNA polymerase for $2 \mathrm{~h}$ according to the manufacturer's protocol. We loaded $2 \mu \mathrm{l}$ of reaction product onto an $8.5 \%$ SDS-polyacrylamide gel. After electrophoresis, the gel was dried and subjected to autoradiography for $2 \mathrm{~h}$.

Nomenclature. We have used the nomenclature of Zhu et al. [17]. Accordingly, the partial sequence obtained from rat brain by Petersen et al. [13] is $M$ trp4 and the human sequences which appear in references [15] and [16] are $\mathrm{H}$ trp1. The full length sequence of M trp1 is deposited in Gene Bank (Accession No. U73625).

\section{Results}

In order to obtain DNA fragments for Northern blotting and cDNA library screening, we performed RTPCR with MIN6 cell and HEK293 cell cDNAs as a template and primers which are designed to amplify all six known trp genes. Six PCR products were analysed from each cell type. For MIN6 cells, five of these corresponded to trp1 and one to trp6, whereas two trp1, three trp3 and one trp6 products were obtained from HEK293 cells. Although trp1, 3, 6 and 2 (which is possibly a pseudogene) show considerable sequence identity, trp4 and trp5 show rather less homology. We therefore carried out RT-PCR with separate primers for trp4 and trp5 and as a result we isolated six trp4 PCR products, but no trp5, from each cell type.

We next screened a MIN6 cDNA library $\left(5 \times 10^{5}\right.$ phages) with a mixed probe consisting of the trp1,3,4 


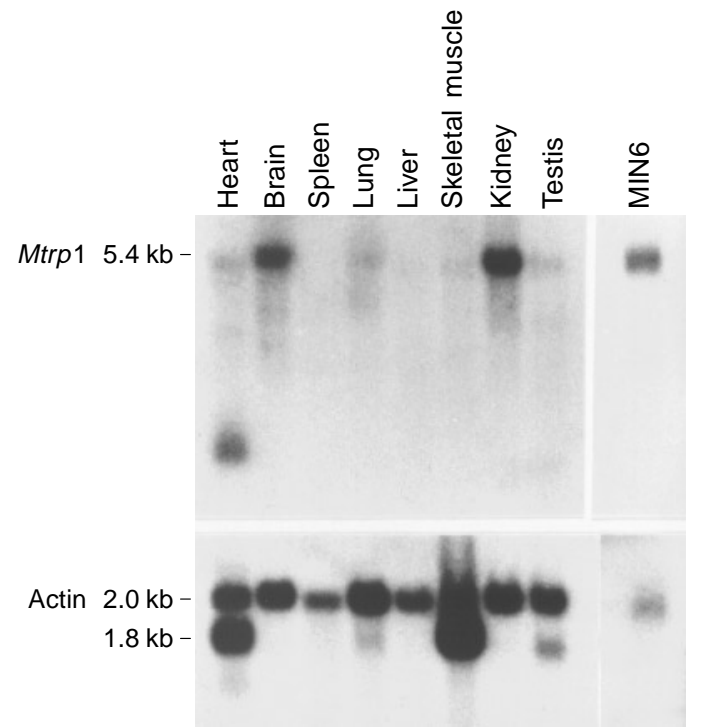

Fig. 1. Northern blot analysis of M trp1 expression. Adult mouse multiple tissue blot and MIN6 total mRNA $(2 \mu \mathrm{g} /$ lane). Upper: Hybridized with $M$ trp1. The signal migrated at $5.4 \mathrm{~kb}$ on each RNA blot. In heart, a $1.4 \mathrm{~kb}$ band was also detected. L ower: Each filter was rehybridized with an actin probe

and 6 fragments we obtained by RT-PCR. Using low stringency hybridisation conditions, we isolated 9 positive clones. Partial sequencing showed that all clones contained the mouse trp1 gene ( $M$ trp1). To determine the tissue distribution of M trp1 expression, we performed Northern blotting under high stringency conditions. As shown in Figure 1, in most tissues a single band of $5.4 \mathrm{~kb}$ was detected. The expression level of M trp1 was very high in MIN6 cells, brain and kidney, less strong in heart, lung, skeletal muscle, testis and liver, and not detectable in spleen. An additional signal at $1.4 \mathrm{~kb}$ was detected in heart. We also performed Northern blot analysis with $\mathrm{M}$ trp3, 4 and 6 as probes, but expression of these genes could not be detected in MIN6 cells, even under low stringency conditions (data not shown).

Since the full length sequence of M trp1 has not been reported, we determined the nucleotide and the deduced amino acid sequences of four trp 1 clones, which on the basis of their insert size were expected to contain the full length coding region. There was 91.1\% homology between the mouse and human trp1 at the nucleotide level and only two amino acids were different (30 [V/A] and $112[\mathrm{~S} / \mathrm{N}])$. As shown in Figure 2A, an additional in-frame methionine codon was found 16 amino acids upstream of the methionine corresponding to the putative initiation codon of human trp1. In the case of human trp1, this additional methionine is replaced with valine (ATGGTG). To determine the translation initiation site of murine trp1 we carried out in vitro translation. The translated product from the ApaI restriction enzyme site, which is located immediately downstream of the first methionine codon of murine trp1, was shorter
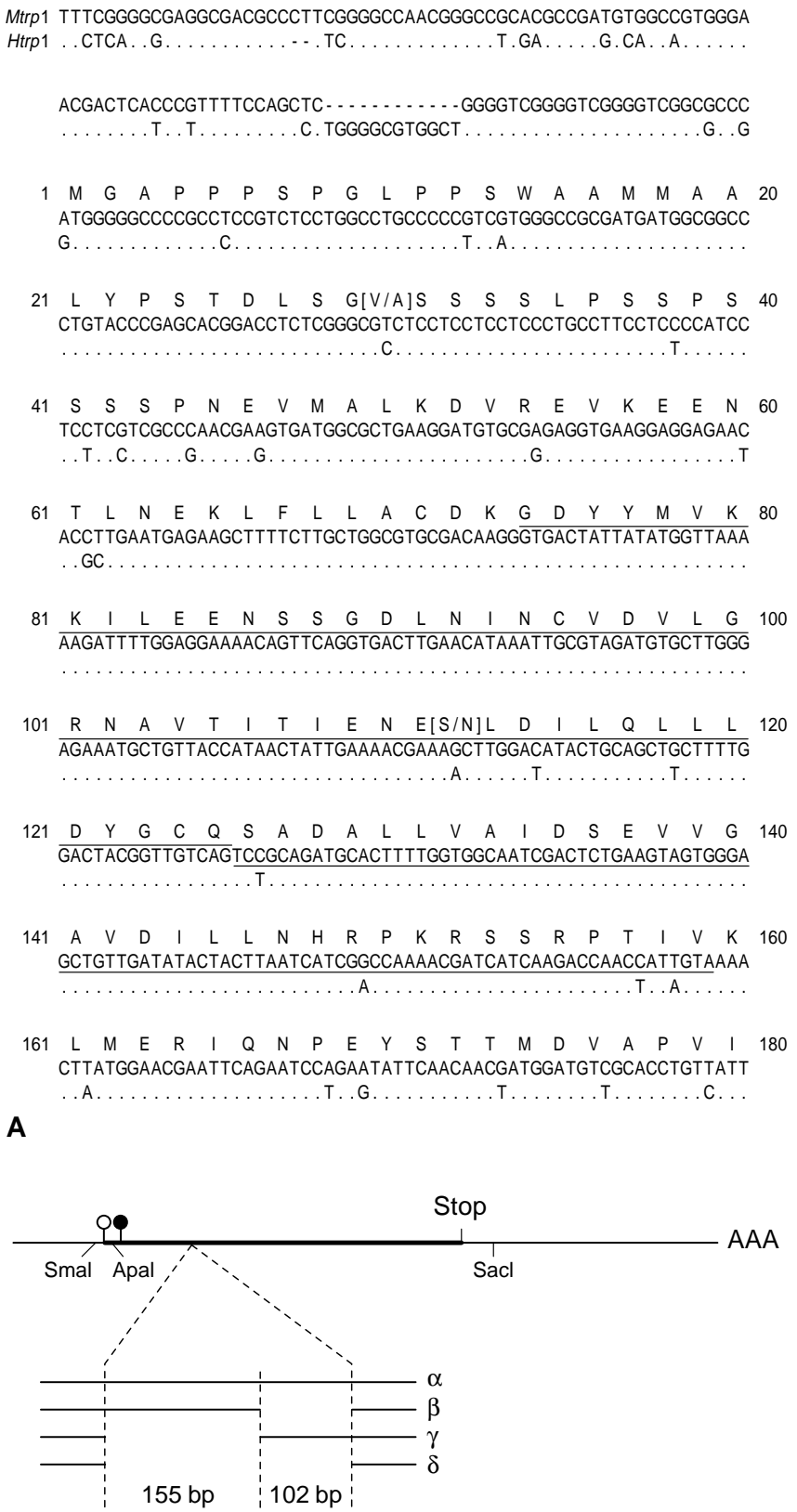

B

Fig. 2A , B. Nucleotide and deduced amino acid sequences of the $M$ trp1 splicing region. A. Alignment of the $M$ trp1 gene with the $\mathrm{H}$ trp1 gene. Hyphens indicate gaps in the alignment and dots represent identical nucleotides in mouse and man. The deduced amino acid is given above the nucleotide sequence. Differences in amino acids (aa) between mouse and man are shown as [mouse aa/human aa]. The nucleotide sequences which are deleted in the splice variants are shown by single underlining and overlining. The $\alpha$ variant has no deletion. The deletions which occur in the $\beta$ and $\gamma$ variants are indicated by underlining and overlining, respectively. The deletions in the $\delta$ variant are marked by both underlining and overlining the sequence. B. The schema shows the putative initiation site, the restriction enzyme sites and the four splicing variants. The closed circle corresponds to the location of the putative initiation methionine of the human trp1. The open circle indicates the location of the first methionine in the murine trp1, and is 16 amino acids upstream of that of human trp1 (represented by the closed circle) 


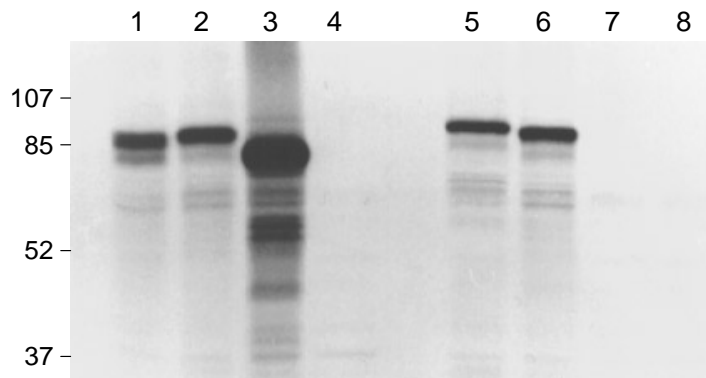

Fig. 3. In vitro translation. Plasmids containing the following inserts were translated using an in vitro reticulocyte system. Lane 1, Full length cDNA ( $\beta$ variant). Lane 2, SmaI-SacI fragment, Lane 3, ApaI-SacI fragment. Lane 4, No DNA, Lane 5$8, \alpha, \beta, \gamma$ and $\delta$ variants (SmaI-SacI fragment). The molecular weight $(\mathrm{kDa})$ is shown on the left

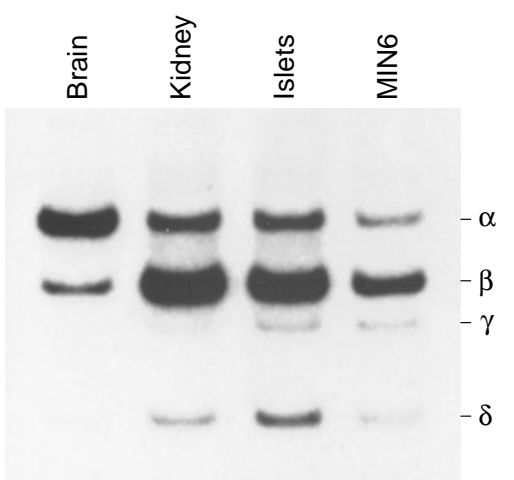

Fig. 4. Four variants of $M$ trp1 were detected by PCR.The sizes of PCR products; $\alpha, \beta, \gamma$, and $\delta$ are 586, 484, 431 and 329 bp, respectively

than that obtained using the full-length clone or the SmaI restriction enzyme site (Figs. 2B and 3). Therefore, the methionine located 16 amino acids upstream of the putative initiation codon of human trp1 may be considered to be the main translation initiation codon of murine trp1. Thus, the translated protein contains 809 amino acids, in contrast to $\mathrm{H}$ trp1 which is 793 amino acids long [14].

During determination of the nucleotide sequence, we found that two clones had the same deletion in the $\mathrm{N}$-terminal region, at a position close to that at which alternative splicing of the human trp1 gene is known to occur [16]. We therefore amplified this region using RT-PCR. As shown in Figure 4 four different bands were detected, which we refer to on the basis of their size as $\alpha, \beta, \gamma$ and $\delta$ variants. Sequencing of each of these PCR products showed that all four variants were produced by alternative splicing, as shown in Figure 2A and B. As the same primers were used in each case, the density of the bands gives an indication of the level of expression. The $\alpha$ type is the major variant in brain, whereas the $\beta$ variant is dominant in kidney, pancreatic islets and MIN6 cells (Fig. 4). In case of the $\gamma$ and $\delta$ variants, a frameshift is introduced, because the deletion of $155 \mathrm{bp}$ cannot be divided by 3 (Fig. 2B). This suggests that these variants are either not expressed, or that an alternative methionine may be used as initiation codon. As shown in Figure 3, only $\alpha$ and $\beta$ variants were efficiently translated. Therefore, the $\gamma$ and $\delta$ variants are considered to be non-functional.

\section{Discussion}

Among the six types of $M$ trp genes which have been reported [17], we found that only $M$ trp1 was expressed at high levels in the insulinoma cell line MIN6. Although M trp 4 and 6 were also identified by PCR the results of Northern blot analysis and screening of cDNA libraries indicated that the expression level of these genes is very low in MIN6 cells.

The expression pattern of trp1 in mouse tissues differs from that reported in man. In the mouse, a strong trp1 mRNA signal of $5.4 \mathrm{~kb}$ was detected in kidney and brain with a less strong signal in heart and testis, whereas in adult man the highest levels of expression are in brain, heart, testis and ovary with only low levels in pancreas and kidney $[14,15]$. $\mathrm{H}$ trp1 is, however, expressed at high levels in fetal kidney. Furthermore, an additional $1.4 \mathrm{~kb}$ band was detected in mouse heart; it is possible that this $1.4 \mathrm{~kb}$ signal comes from a gene related to $M$ trp1.

We identified four splicing variants of M trp1. Of these, only the $\alpha$ and $\beta$ variants have been identified for human $\operatorname{trp} 1(\mathrm{H} \operatorname{trp} 1,[7,8])$ : the $\gamma$ and $\delta$ variants have not been reported. The RT-PCR results reported in this study suggest that the $\gamma$ and $\delta$ variants are only a minor component of $\mathrm{M}$ trp1 in all tissues examined. Furthermore, in vitro translation studies indicate that these proteins are unlikely to be expressed (although it is possible that expression may be different in tissues other than rabbit reticulocytes). The M trp1 $\beta$ variant was the dominant variant in MIN6 cells. The results of RT-PCR suggest this may also be the case for pancreatic islets.

Hydrophobicity analysis suggests that, like other members of the trp family, the M trp1 protein has six putative transmembrane domains and a pore loop between domains 5 and 6 . This predicted topology is similar to that of each of the four repeats of the voltage-dependent calcium channel (VDCC). Unlike the calcium channel, however, there are no charged amino acids in the fourth transmembrane domain of $M$ trp1 (which in VDCC is believed to act as the voltage sensor). This suggests that the M trp1 channel will be voltage-independent.

Functional studies have suggested that the $\mathrm{H} \operatorname{trp} 1 \beta$ variant encodes a non-selective cation channel which is permeable to both $\mathrm{Na}^{+}$and $\mathrm{Ca}^{2+}$ [16]. This 
channel also appears to be activated by depletion of intracellular $\mathrm{Ca}^{2+}$ stores [16]. The dominant expression of the M trp1 $\beta$ variant in MIN6 cells suggests that this gene may encode a non-selective cation channel in pancreatic beta-cells. This may correspond to the non-selective $\mathrm{I}_{\mathrm{CRAC}}$ current reported in betacells by Worley et al. [7]. Whether it may also underlie the $\mathrm{Na}^{+}$-entry that is activated by acetylcholine stimulation of muscarinic $m 3$ receptors [2-5] remains to be determined. It is worth noting, however, that capacitative $\mathrm{Ca}^{2+}$ entry in $\mathrm{X}$ enopus oocytes may be enhanced by G-proteins [13], and that $\mathrm{m} 3$ receptors are believed to mediate their effects via G-protein activation. Since the $H$ trp $1 \beta$-variant encodes a non-selective cation channel, it is also possible that the beta-cell background inward current, which is responsible for depolarizing the beta-cell when K-ATP channels close, may be encoded by the M trp1 gene. A detailed comparison of the properties of both currents will be necessary to determine if this idea is correct.

Acknowledgements. We thank the Wellcome Trust and the British Diabetic Association for support.

\section{References}

1. Ashcroft FM, Rorsman P (1989) Electrophysiology of the pancreatic $\beta$-cell. Prog Biophys Molec Biol 54: 87-143

2. Gilon P, Henquin JC (1993) Activation of muscarinic receptors increases the concentration of free $\mathrm{Na}^{+}$in mouse pancreatic B-cells. FEBS Lett 315: 353-356

3. Bertram R, Smolen P, Sherman A et al. (1995) A role for calcium release-activated current (CRAC) in cholinergic modulation of electrical activity in pancreatic B-cells. Biophys J 68: 2323-2332

4. Henquin JC, Garcia MC, Bozem M, Hermans MP, Nenquin M (1988) Muscarinic control of pancreatic B-cell function involves sodium-dependent depolarization and calcium influx. Endocrinol 122: 2134-2142

5. Miura Y, Gilon P, Henquin JC (1996) Muscarinic stimulation increases $\mathrm{Na}^{+}$entry in pancreatic B-cells by a mechanism other than the emptying of intracellular $\mathrm{Ca}^{2+}$ pools. Biochem Biophys Res Commu 224: 67-74
6. Leech CA, Holz GG, Habener JF (1995) Pituitary adenylate cyclase activating polypeptide induces the voltage-independent activation of inward membrane currents and elevation of intracellular calcium in HIT T15 insulinoma cells. Endocrinol 136: 1530-1536

7. Worley III JF, McIntyre MS, Spencer B, Dukes ID (1994) Depletion of intracellular $\mathrm{Ca}^{2+}$-stores activates a maitotoxin-sensitive nonselective cationic current in beta-cells. J Biol Chem 269: 32055-32058

8. Worley III JF, McIntyre MS, Spencer B, Mertz RJ, Roe MW, Dukes ID (1994) Endoplasmic reticulum calcium store regulates membrane potential in mouse islet B-cells. J Biol Chem 269: 14359-14362

9. Leech CA, Holtz IV GG, Habener JF (1994) Voltage-independent calcium channels mediate slow oscillations of cytosolic calcium that are glucose dependent in pancreatic Bcells. Endocrinol 135: 365-372

10. Berridge MJ (1996) Capacitative calcium entry. Biochem J 312: 1-11

11. Friel DD (1996) Trp: its role in phototransduction and store-operated $\mathrm{Ca}^{2+}$. Cell 85: 617-619

12. Vaca L, Sinkins WG, Hu Y, Kunze DL, Schilling WP (1994) Activation of recombinant trp by thapsigargin in Sf9 insect cells. Am J Physiol 267:C1501-C1505

13. Petersen $\mathrm{CCH}$, Berridge $\mathrm{MJ}$, Borgese MF, Bennett DL (1995) Putative capacitative calcium entry channels: expression of D rosophila trp and evidence for the existence of vertebrate homologues. Biochem J 311: 41-44

14. Zhu X, Chu PBM, Peyton M, Birnbaumer L (1995) Molecular cloning of a widely expressed human homologue for the D rosophila trp gene. FEBS Lett 373: 193-198

15. Wes PD, Chevesich J, Jeromin A, Rosenberg C, Stetten G, Montell C (1995) TRPC1, a human homolog of a D rosophila store-operated channel. Proc Natl Acad Sci USA 92: 9652-9656

16. Zitt C, Zobel A, Obukhov AG et al. (1996) Cloning and functional expression of a human $\mathrm{Ca}^{2+}$-permeable cation channel activated by calcium store depletion. Neuron 16 : 1189-1196

17. Zhu X, Jiang M, Peyton M, Boulay G, Hurst R, Stefani E, Birnbaumer L (1996) trp, a novel mammalian gene family essential for agonist-activated capacitative $\mathrm{Ca}^{2+}$ entry. Cell 85: 661-671

18. Sakura H, Ämmälä C, Smith PA, Gribble FM, Ashcroft FM (1995) Cloning and functional expression of the cDNA encoding a novel ATP-sensitive potassium channel expressed in pancreatic $\beta$-cells, brain, heart and skeletal muscle. FEBS Letts 377: 338-344 